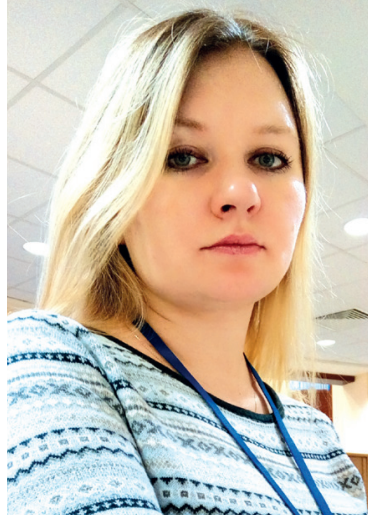

\section{Сурнина Ирина Александровна}

кандидат филологических наук, доцент, факультет журналистики, Московский государственный университет имени М. В. Ломоносова, 125009, Российская Федерация, г. Москва, ул. Моховая, 9, e-mail: isurnina1983@mail.ru

\section{Irina A. Surnina}

$\mathrm{PhD}$ in Philology, Associate Professor, Department of Journalism, Lomonosov Moscow State University, 9 Mokhovaya St., 125009, Moscow, Russian Federation, e-mail: isurnina1983@mail.ru

\title{
КРАТКИЙ ОЧЕРК ЖИЗНИ М. Я. КИТТАРЫ
}

Аннотация. Личность и деятельность М. Я. Киттары до сих пор не привлекли должного внимания исследователей. Вероятно, вызвано это тем, что архив его не сохранился, что весьма затрудняет работу по составлению полноценной биографии данного ученого. До наших дней дошли лишь некоторые сведения, относящиеся к начальному периоду его научной и журналистской деятельности (пермский, казанский).

Автор статьи впервые пытается собрать воедино данные о жизни и деятельности М. Я. Киттары: его работа в Казанском и Московском университетах, воспоминания современников о его преподавании, редакторская и журналистская деятельность. Особое внимание уделено в статье хлопотам Киттары об открытии экономической газеты «Промышленный листок», выходившей на рубеже 50-60 гг. XIX в.

Также впервые в статье анализируется духовное завещание Киттары, оставленное им после смерти, где были отражены его заботы и переживания по поводу промышленного образования простого народа (открытое им училище для крестьянских детей в селе Новое и пожертвование денег на дальнейшую работу).

Ключевые слова. М. Я. Киттары, журналистика, «Промышленный листок», образование крестьянских детей.

Информация о статье. Дата поступления 1 декабря 2016 г.; дата принятия к печати 19 января 2017 г.; дата онлайн-размещения 31 января 2017 г.

\section{YA. KITTARY'S PROFILE}

Abstract. M. Ya. Kittary's personality and contribution to journalism still have not been studied by modern researchers well enough. His archives have been lost and, therefore, writing his full biography is rather difficult. We have very little information about the beginning of his scientific and journalistic career in Perm and Kazan.

The author of the article is trying to bring together facts from M. Ya. Kittary's life and career: his working at Kazan University and Moscow 
University, his peers' recollections of his methods of teaching, his working as an editor and a journalist. The article describes in detail Kittary's contribution to starting an economic newspaper, Promyshlenniy Listok (Industrial Bulletin), which was published at the turn of the 1860s. Having studied files of the Russian State Historical Archive the author of the article depicts the hard work a $19^{\text {th }}$ century editor had to perform to receive permission to have a publishing house.

Kittary's last will where he stated his concerns about educating rural children is analyzed for the first time in the article. Kittary opened a school for children of the village Novoye and donated a sum of money for the school to be further developed.

Keywords. M. Ya. Kittary, journalism, Promyshlenniy listok, educating rural children.

Article info. Received December 1, 2016; accepted January 19, 2017; available online January 31, 2017.

М. Я. Киттары - заметная фигура в истории русский науки и журналистики. Его специальность в первую очередь - химия и технология. Он - известный профрессор Московского университета с 1859 г., редактор нескольких экономических изданий, среди которых газета «Промышленный листок», выходившая в Москве в 1858-1859 гг. Его основные работы: «Очерк современного положения и нужд русской мануфактурной промышленности (1857), «Публичный курс товароведения» (1860), «Лекции технологии» (1861), «Лекции о кожевенном производстве» (1865), «Публичный курс винокурения» (1866) и др. Имя Киттары было известно не только в России, но и в Западной Европе и в Америке ${ }^{1}$ : изобретенная им машина для сортировки сукон (вореометр) удостоилась золотой медали на Всемирной выставке в Филадельфии, а его труд «Кожевенное производство в России» издано в Соединенных штатах Америки на английском и немецком языках ${ }^{2}$. Остановимся подробнее на основных моментах его биографии.

$$
\text { C. } 3 \text {. }
$$

${ }^{1}$ Современные известия. 1880. № 191.
Модест Яковлевич Киттары родился в Перми 22 ноября 1824 г. (о годе рождения М. Я. Киттары сведения разнятся, большинство справочных материалов, например, Русский биографический словарь (Издан под наблюдением Императорского Русского Исторического Общества А. А. Половцева. СПб., 1897. Т. 9 (Ибак-Ключарев) С. 726727), Энциклопедический словарь Ф. А. Брокгауза и Э. А. Ефррона (СПб., 1907. Т. 15(29). С. 235) указывают на 1825 г., однако на его усыпальнице в качестве даты рождения стоит именно 22 ноября 1824 г. И. С.) в семье ссыльного польского дворянина [1, с. 71]. После обучения в пермской гимназии юный Киттары поступил в Казанский университет, который окончил по разряду естественных наук в 1844 г.

Спустя семь лет он отправился в Лондон на Всемирную выставку. Целью данной поездки стала научная оценка представленных там экспонатов. После возвращения из Лондона Киттары составил отчет, где представил анализ экспозиции. ОН вышел в Казани отдельным изданием. Полученный опыт помог ему в дальнейшем при организации Казан- 
ской выставки сельских произведений, проведенной в 1852 г., и Вятской окружной выставки, состоявшейся в 1854 г. Примечательно, что Киттары в 1862 г. был вновь командирован в Лондон, по этому случаю А. В. Никитенко записал в своем дневнике 20 марта того же года: «Утвердили корреспондента в Лондоне по случаю всемирной выставки - московского профессора Киттары» [2, с. 343] (с 1857 года Киттары преподавал в Московском университете. - И. С.).

В 1853 г. Киттары занял должность ординарного профессора по кафедре технологии в Казанском университете [3, с. 2]. У студентов он пользовался большим уважением и любовью. Спустя годы многие из них отзывались о его преподавании исключительно положительно. Так, Д. А. Корсаков в своих «Воспоминаниях о прошлом» писал: «Весьма характерно, что среди всех <...> профрессоров, только Мод<ест> Яковл<евич> Киттары, профессор технологии $<\ldots . .>$ не осмеян студентами. Ему, напротив, воссоздано истинное почтение даже в этом шутливом песнопении, в следующих выражениях:

\section{Модесту Киттары \\ Славу мы поем, - \\ Да хранят же Лары \\ Его кров и дом» [4, с. 28].}

В. А. Лебедев отмечал: «Киттары был очень знающий профрессор; по лекциям его видно было, что он в своем предмете, как рыба в воде; много интересовался он местной казанской промышленностью; посещал местные заводы и, конечно, не без противодействия их владельцев, давая указания для улучшения производства, оставшиеся, вероятно, гласом вопиющего в пустыне» [5, с. 246-246]. Для студентов, изучающих камералистику (Камерали- стика - наука об административных и экономических вопросах. - И. С.), Киттары был незаменимым преподавателем, ее «энергичным заступником и пропагатором»: «Правда, что он орудовал очень усердно, стараясь заинтересовать своих слушателей обследованием и изучением местных отраслей заводской промышленности и печатанием их письменных работ и наблюдений <...> По своему добродушию, участливому вниманию к интересам молодежи, по желанию быть ей полезным Киттары был прямо идеальным человеком» [7, с. 245-247]:

Модесту Киттары

Общая любовь! [Там же, с. 247].

П. Д. Боборыкин назвал Киттары «самым популярным у камералистов» [6, с. 96]. Им же замечено, что почти все студенты данного направления работали у ученого в лаборатории, «выбирая темы для своих кандидатских диссертаций» [7, с. 74]. Читал Киттары студентам и практическую механику и технологию, причем «читал занимательно, живо, разнообразно» [Там же, с. 79-80].

Примечательно, что Киттары помогал также своим студентам и в организации внеклассной деятельности. Однажды они загорелись идеей организовать бал, но «струхнули немного $\langle\ldots\rangle$, боялись "провалиться"», но «весь город заинтересовался студенческим балом, и в несколько дней Киттары, взявший на себя главное распорядительство, все наладил, и бал вышел на славу» [7, с. 76].

Также Киттары читал в химической аудитории университета для всех желающих бесплатные публичные лекции по химии и технологии, которые были весьма популярны в Казани. Современники высоко ценили преподавательскую деятельность Киттары: «...своим преподаванием, 
своими работами, публичными чтениями, руководствами и статьями в первый раз ввел в изучение рациональные методы в фабрично-заводскую промышленность целого Поволжкого края» [3, с. 2].

При деятельном участии Киттары при Казанском университете открыли технический музей: собственными руками он собрал около 900 образцов разнообразных технических продуктов и опубликовал по ним каталог.

В 1854-1857 гг. Киттары принимал деятельное участие в Казанском экономическом обществе (открылось в 1839 г.), будучи его секретарем. В те же годы основал журнал общества и стал его редактором и автором, опубликовав более 150 материалов по различным вопросам промышленного развития. Корсаков вспоминал «В "Записках" этих годов возбуждались вопросы экономические, затрагивалось крепостное право - центральный нерв тогдашней публицистики, а потому этот журнал обратил на себя серьезное внимание столичной прессы. Все толки и крики, больше крики, которые раздаются в наши дни о важности экономических факторов в народной жизни, ○ поднятии кустарных промыслов и об улучшении земледельческой культуры, - все это неудержимое стремление к профессиональному, технически-ремесленному образованию- могут по меньшей мере вызывать удивление и улыбку у тех, кто знавал такого рода серьезного ученого и практического деятеля, как Мод<ест> Як<овлевич> Киттары; свои рациональные воззрения по этим вопросам научно и скромно проводил он в казанскую жизнь» [4, с. 95].

Благодаря проектам профрессора в Казани открылись такие крупные заводы, как стеариновый завод братьев Крестовниковых и кожевенный завод Алафузовых: «два самых крупных казанских завода, Крестовникова и Алафузова, всецело обязаны ему своим процветанием» [4, с. 94].

В 1857 г. профессор переехал в Москву. Московские купцы и фабриканты ходатайствовали об открытии кафедры технологии в Московском университете. Именно там Киттары и продолжил преподавательскую деятельность: в 1857-1879 гг. он работал на кафредре технологии, сельского хозяйства, лесоводства и архитектуры ффизико-математического фракультета. В 1859 г. Киттары возглавил технологическую лабораторию университета, а в 1867 г. по его инициативе при университете открыли Технический музей и лабораторию.

Помимо Московского университета Киттары также читал лекции по химической технологии и аналитической химии в Московском ремесленном училище и руководил Московской практической академией коммерческих наук.

В 1858-1859 гг. он редактировал экономическую газету «Промышленный листок», выходившую в Москве. Причем прошение о ее издании он подал в Московский цензурный комитет, еще проживая в Казани. В Санкт-Петербурге в Российском государственном историческом архиве хранится дело о дозволении профессору Казанского университета Киттары издавать газету «Промышленный листок» ${ }^{3}$.

История газеты началась в июне 1857 г. Именно тогда профессор Казанского университета отправил в Москву письмо с просьбой о разрешении ему издавать в Москве газету: «Желая быть полезным отечествен-

3 Российский государственный исторический архив (РГИА) . Ф. 772. Оп. 1. Д. 4209. Л. 1-17. 
ной промышленности, я намерен с 1857 года издавать газету под названием "Промышленный листок". Прилагая программу предполагаемой газеты, я имею честию покорнейше просить Московский цензурный комитет о разрешении мне вышеупомянутого издания. Казань. 21 июня 1857 года» ${ }^{4}$.

Цель будущей газеты Киттары определил так: «постоянно знакомить публику с ходом и состоянием различных отраслей промышленности и торговли, как отечественной, так и иностранной; своевременно сообщать все новое и интересное в промышленном мире, наконец, облегчить взаимные сношения лиц, посвятивших себя промышленности» ${ }^{5}$.

Согласно правилам о прошениях на разрешение изданий периодических органов, Киттары приложил подробную программу «Промышленного листка». В газете он планировал следующие отделы: I) «Меры правительства и административные распоряжения (как общие, так и частные, касающиеся всех отраслей промышленности и торговли). II) Известия отечественные. Промышленные. О сельском хозяйстве, заводах, фабриках, о частных открытиях, улучшениях, изобретениях с критической их оценкой и с приложением, по надобности, чертежей и рисунков. Торговля: о ценности товаров и сырых произведений, о движении ярмарок, судоходства, железных дорог, о запросе, ввозе и вывозе, ценности акций, сравнительном курсе и пр.). III) Известия иностранные того же содержания о других государствах. IV) Корреспонденции и извещения. Краткие вопросы и ответы редакции по промышленности и торговле, сношения с иностранны-

\footnotetext{
${ }^{4}$ РГИА. Ф. 772. Оп. 1. Д. 4209. Л. 2.

${ }^{5}$ Там же. Л. 3.
}

ми торговыми домами; извещения о различных предметах запроса и сбыта в области той же промышленности и торговли, о воспитанниках практических промышленно-учебных заведений, предлагающих услуги. V) Прибавление к «Промышленному листку». Письма, беседы, рассказы и другие популярные статьи по различным вопросам промышленности и торговли» ${ }^{6}$ (здесь и далее - подчеркивание М. Я. Киттары).

Отмечалось, что «Промышленный листок» будет издаваться в Москве от одного до двух раз в неделю7. Каждый номер должен заключать от 1 до 4 печатных листов.

Московский цензурный комитет оснований для отказа не нашел (на запрос Комитета в Казанский университет ответили, что «г. Киттары во все время службы своей в Казанском Университете всегда отличался благонамеренным образом мыслей» ${ }^{8}$ ). Кроме того, комитет отправил запросы Господину Министру финансов ${ }^{9}$ и Господину Главному начальнику III Отделения Собственной Его Императорского Величества Канцелярии ${ }^{10}$. Никаких возражений с их стороны не последовало ${ }^{11}$.

Также Московский цензурный комитет 23 августа 1857 г. переадресовал в Главное управление цензуры прошение Киттары, где он излагал свои планы на издание «газеты под названием «Промышленный листок», которая станет выходить ежемесячно; в случае же неудобства редактор предоставляет себе право выпускать оную газету в неделю два раза» ${ }^{12}$. Здесь необходимо отметить, что,

\footnotetext{
${ }^{6}$ Там же. Л. 3-3 об.

${ }^{7}$ Там же. Л. 3 об.

${ }^{8}$ Там же. Л. 1 об.

9 Там же. Л. 4-4 об.

${ }^{10}$ Там же. Л. 5-5 об.

11 Там же. Л. 6-7.

12 Там же. Л. 1.
} 
вероятно, газета задумывалась Киттары как журнал, с большим объемом, подобно «Запискам», которые он редактировал в Казани, но «Промышленный листок» был небольшим по объему и выходил 2 раза в неделю. Видимо, Киттары решил отказаться от первоначального замысла.

По истечении нескольких месяцев Киттары, известный «своими способностями, учеными сведениями и вполне одобрительным образом мыслей» ${ }^{13}$, получил дозволение на издание испрашиваемого периодического издания. Положительный ответ пришел в Москву 15 ноября: Киттары разрешили с начала 1858 г. выпускать газету «Промышленный листок ${ }^{14}$.

Газета выходила менее полутора лет (до конца марта 1859 г.), впоследствии Киттары соединил ее с газетой П. И. Мельникова-Печерского «Русский дневник».

Каких-либо предупреждений газете не выносилось, и за все время ее выхода Главное управление цензуры заинтересовали всего две статьи «Письмо с Урала» и «Замечания ○ существенных интересах русских землевладельцев-помещиков и крестьян ${ }^{15}$. Но, тем не менее, графр А. А. Закревский в год своего увольнения с поста генерал-губернатор Москвы (1859. - И. С.), составил для князя В. А. Долгорукова, идущего ему на смену, список подозрительных лиц, куда вошел и Киттары «без обозначения причины» [8, с. 40].

Служебная карьера Киттары продолжалась, и с 1860 г. его назначили секретарем Московского общества сельского хозяйства [9, с. 94-95]. В 1860 г. он получил золотую медаль

\footnotetext{
${ }^{13}$ РГИА. Ф. 772. Оп. 1. Д. 4209. Л. 8-9.

14 Там же. Л. 13-14 об.

${ }^{15}$ Там же. Д. 4468. Л. 1-4.
}

Вольного экономического общества за изобретение простого и дешевого способа изготовления консервов (вышел отдельной брошюрой «Русская печь как средство к приготовлению консервов». - И. С.).

Также по инициативе бывшего военного министра Н. О. Сухозанета Киттары пригласили для чтения интендантским чиновникам курсов технологии и товароведения. Позднее он был назначен председателем технического комитета при Главном интендантском управлении военного министра [3, с. 470-471; 10, с. 470-471].

В начале 1860 гг. Киттары приобрел в собственность село Новое (при деревне Горетовке, которая существует и в наши дни, расположена по Пятницкому шоссе и относится к городскому поселению Андреевка. И. С.), находящееся в 36 верстах от Москвы, в 4 верстах от Крюковской станции Николаевской железной дороги ${ }^{16}$. Первое, на что он обратил внимание, это на бедность крестьян соседних деревень. С целью поднять их материальный быт, дать возможность крестьянам заработать деньги он устроил в своем имении заводы и "разные мастерства» ${ }^{17}$.

В то время профрессор еще не имел возможности на свои средства построить здание училища и нанять учителей для обучения крестьян, но это его не остановило. Он в собственном доме организовал училище для крестьянских детей, пригласил местного священника для законоучительства, а свою сестру - учительницей. Таким образом, школа все-таки открылась, в ней обучалось 9 мальчиков. Однако, к сожалению, через три года школа закрылась. Вызвано это было несколькими причи-

\footnotetext{
C. 2 .

17 Там же.
}

${ }^{16}$ Современные известия. 1881. № 16. 
нами: Киттары постоянно проживал в Петербурге, а сестра его, не отличавшаяся крепким здоровьем, не могла давать уроки постоянно. Уже позднее, в 1877 г., Киттары возобновил проект. Теперь для школы началось строительство отдельного здания. Он закупил мебель для занятий в классах, учебные пособия и вскоре с позволения училищного совета в селе Новое открылось одноклассное училище. В первый год набор прошел отлично, зачислили 42 ученика, а через год еще более. Со временем училище преобразовали в двуклассное по образцу училищ Министерства народного просвещения. Киттары сам неоднократно посещал классы и экзамены, контролировал обучение, и вскоре его училище стало одним из лучших в Московском уезде.

Будучи техником, Киттары понимал, что крестьянским детям необходимо обучаться не только грамоте, но и ремеслам. Он собирался открыть в 1880 г. при училище ремесленные классы, чтобы после окончания выпускник мог заниматься практической деятельностью. Однако замыслу этому не удалось реализоваться. В марте 1880 г. Киттары не стало, он умер после продолжительной и мучительной болезни печени ${ }^{18}$. Похоронен в Московской губернии близ Спасского храма (построен в 1676-1678 гг. - И. С.), который существует и по сей день (расположен в Андреевка Солнечногорского района Московской области. - И. С.). Место было выбрано неслучайно: сельцо Новое, приобретенное им в собственность за 20 лет до смерти, находилось совсем рядом. Над могилой его возведена часовня-усыпальница с бюстом покойного и над-

${ }^{18}$ Современные известия. 1881. № 16. C. 2. писью: «"И делал он благое дело, / Надеясь, веруя, любя..." Господи, прими дух его с миром и сотвори ему добрую память в людях».

Однако и, умирая, он не забыл об училище и в духовном завещании «поручил своим душеприказчикам внести капитал в 10000 р. в Министерство народного просвещения с тем, чтобы оно взяло под свое ведение его двухклассную школу и содержало ее на собственный счет», также он завещал «отдать в собственность министерства десятину земли и здание училища со всеми принадлежностями и имуществом в нем» ${ }^{19}$. Здесь необходимо отметить, что в духовном завещании он также пожертвовал из оставшегося после него имущества 20000 р. на устройство народных школ в Казанском учебном округе ${ }^{20}$.

Но, как оказалось, процентов с пожертвованного капитала не хватило, и тогда один из душеприказчиков Киттары, его зять, бывший преподавателем Тверской семинарии, И. А. Виноградов обратился в Министерство народного просвещения к статс-секретарю А. А. Сабурову с просьбой в память о заслугах покойного профессора поддержать училище и выделить сверх основной дополнительную сумму. Просьба его была уважена, и с 1 января 1881 г. «Министерством разрешено открыть двуклассное училище в сельце Новом Московского уезда и отпускать на содержание училища 675 рублей в добавок к получаемым с завещанного г. Киттары капитала процентам» ${ }^{21}$. Открытие началось с панихиды по усопшему основателю училища, так горячо заботившемуся о народном образовании.

\footnotetext{
19 Там же.

20 Там же. 1880. № 184. C. 3.

21 Там же.
} 
Заметим, что также в последние годы своей жизни Киттары в имении открыл завод для производства свинцовых белил. Одной из основных целей данного предприятия стало «показать на практике, как должен быть устроен такой завод на рациональных основаниях без ущерба здоровью рабочих» [3, с. 470-471]. После смерти Киттары завод оказался в центре судебного разбирательства: решался вопрос, кому достанутся недозрелые белила, хранившиеся в чушках на заводе $\mathrm{e}^{22}$.

$$
* * *
$$

Киттары выступал за развитие промышленности, за улучшение условий производства, приветствовал быстрый рост купеческого сословия C. 3.

${ }^{22}$ Современные известия. 1880. № 286. в пореформенную эпоху, ратовал за улучшение его образования (за открытие различных учебных заведений, где купцы могли бы совершенствовать и углублять свои знания). Его ученая деятельность по технологии много способствовала развитию в России технических усовершенствований на фабриках и заводах.

Кроме этого значителен его вклад в развитие отечественной журналистики как редактора экономических изданий, автора многих статей на темы промышленности и торговли: Киттары «жил интересами русской промышленности, печаловался ее печалями, сокрушался о ее косности и, конечно, мог принести много пользы интендантству $<\ldots>$ он стал приноравливаться к людям и обстоятельствам для проведения своих идей» [5, с. 245-247].

\section{СПИСОК ИСПОЛЬЗОВАННОЙ ЛИТЕРАТУРЫ}

1. Уткин А. А. Либеральная интеллигенция Казани на рубеже 50-60 годов XIX века : дис. ... канд. ист. наук : 07.00.02 / А. А. Уткин. - Казань, 2002. - 213 с.

2. Никитенко А. В. Записки и дневник : в 3 т. / А. В. Никитенко. - М. : Захаров, 2005. T. 2. -608 c.

3. Киттары, Модест Яковлевич [1825 - 28 марта 1880] - рус. химик-технолог [некролог] / подгот. Половцов / / Новое время. - 1880. - № 1467.

4. Корсаков Д. А. Былое из казанской жизни 1856-1860 годов (воспоминания о прошлом) / Д. А. Корсаков // Литературный сборник. - Казань : Изд. «Волжского Вестника», 1898. - С. 259-355.

5. Лебедев В. А. Учебные воспоминания / В. А. Лебедев // Русская старина. 1908. - Т. 136, № 10. - С. 245-264..

6. Боборыкин П. Д. Воспоминания : в 2 т. / П. Д. Боборыкин. - М. : Худож. лит., 1965. - T. 1. - 567 c.

7. Боборыкин П. Д. За полвека. Воспоминания / П. Д. Боборыкин. - М. : Захаров, 2003. $-670 \mathrm{c}$.

8. Барсуков Н. П. Жизнь и труды М. П. Погодина : в 22 т. / Н. П. Барсуков. - СПб. : Погодин и Стасюлевич, 1903. - Т. 17. - 494 с.

9. Кошелев А. И. Записки Александра Ивановича Кошелева (1812-1883 годы) : С семью прил. / А. И. Кошелев ; изд. подгот. Т. Ф. Пирожкова. - М. : Наука, 2002. - 492 с.

10. Дельвиг А. И. Полвека русской жизни / А. И. Дельвиг. - М. : Терра : Книжный клуб Книговек, 2015. - 797 с.

\section{REFERENCES}

1. Utkin A. A. Liberal'naya intelligentsiya Kazani na rubezhe 50-60 godov XIX veka. Kand. Diss. [Liberal Intellectuals at the Turn of 1850s. Cand. Diss.]. Kazan, 2002. 213 p.

2. Nikitenko A. V. Zapiski i dnevnik [Memoirs and Diary]. Moscow, Zakharov Publ., 2005. Vol. 2.608 p. 
3. Polovtsov (ed.). Modest Yakovlevich Kittary (1825 - 28 March 1880). a Russian Chemical Engineer (Obituary). Novoe vremya = The New Times, 1880, no. 1467. (In Russian).

4. Korsakov D. A. Kazan in 1856-1860 (Old Times Memoirs). Literaturnyi sbornik [Short Stories Selection]. Kazan, Volzhskii Vestnik Publ., 1898, pp. 259-355. (In Russian).

5. Lebedev V. A. Learner's Memoirs. Russkaya starina $=$ Old Times in Russia, 1908, vol. 136, no. 10, pp. 245-264. (In Russian).

6. Boborykin P. D. Vospominaniya [Memoirs]. Moscow, Khudozhestvennaya literatura Publ., 1965. Vol. 1. 567 p.

7. Boborykin P. D. Za polveka. Vospominaniya [For Half a Century. Memoirs]. Moscow, Zakharov Publ., 2003. 670 p.

8. Barsukov N. P. Zhizn' i trudy M. P. Pogodina [Life and Works of M.P. Pogodin]. Saint Petersburg, Pogodin \& Stasyulevich Publ., 1903. Vol. 17. $494 \mathrm{p.}$

9. Koshelev A. I. Zapiski Aleksandra Ivanovicha Kosheleva (1812-1883 gody) [Alexander I. Koshelev's Memoirs (1812-1883)]. Moscow, Nauka Publ. 2002. 492 p.

10. Del'vig A. I. Polveka russkoi zhizni [Half a Century of Living in Russia]. Moscow, Terra Publ., Books Club Knigovek Publ., 2015. 797 p.

\section{БИБЛИОГРАФИЧЕСКОЕ ОПИСАНИЕ СТАТЬИ}

Сурнина И. А. Краткий очерк жизни М. Я. Киттары / И. А. Сурнина / / Вопросы теории и практики журналистики. - 2017. - Т. 6, № 1. - С. 68-76. - DOI : 10.17150/23086203.2017.6(1).68-76.

\section{REFERENCE TO ARTICLE}

Surnina I. A. M. Ya. Kittary's Profile. Voprosy teorii $i$ praktiki zhurnalistiki $=$ Theoretical and Practical Issues of Journalism, 2017, vol. 6, no. 1, pp. 68-76. DOI: 10.17150/23086203.2017.6(1).68-76. (In Russian). 